\title{
Research on Issues and Policy Evaluative Factors of Implementing Distributed Photovoltaic Power Generation in Frontier Rural Areas of China
}

\author{
Gang Feng ${ }^{1, ~ *, ~ K a z u h i s a ~ I n o u e ~}{ }^{1}$, Shinichi Tomonari ${ }^{2}$ \\ ${ }^{1}$ Graduate School of Environment and Energy Engineering, Waseda University, Saitama, Japan \\ ${ }^{2}$ Faculty of Science and Engineering, Waseda University, Tokyo, Japan
}

Email address:

hyogoyc@gmail.com (Gang Feng), ikazu@toki.waseda.jp (K. Inoue), tomonari@waseda.jp (S. Tomonari)

*Corresponding author

\section{To cite this article:}

Gang Feng, Kazuhisa Inoue, Shinichi Tomonari. Research on Issues and Policy Evaluative Factors of Implementing Distributed Photovoltaic Power Generation in Frontier Rural Areas of China. Journal of Energy and Natural Resources. Vol. 6, No. 3, 2017, pp. 31-37. doi: $10.11648 /$ j.jenr.20170603.11

Received: April 7, 2017; Accepted: June 1, 2017; Published: June 6, 2017

\begin{abstract}
This paper firstly analyzes the evaluative factors of relevant policies in implementing distributed photovoltaic power generation in frontier rural areas of China based on prior study. Then, by using these factors, the author investigates the first pilot project for poverty alleviation with distributed photovoltaic power generation in Xinjiang Uygur Autonomous Region. According to the investigation, the effects of this project are embodied in its policy implications, that is, having a positive effect on energy security and national amalgamation of China. In view of the financial difficulty faced by the project, this paper puts forward constructive suggestions for improvement learning from the experience of photovoltaic power generation project in Iida City, Nagano Prefecture, Japan. In the future, promoting diversified social capital injection and villagers' participation in the implementation of the project will be a crucial task.
\end{abstract}

Keywords: Distributed Photovoltaic Power Generation, Poverty Alleviation, Frontier Rural Areas

\section{Introduction}

The People's Republic of China published Renewable Energy Law on January 1, 2006. This law aims to promote the development and utilization of renewable energy, increase energy supply, improve energy structure, ensure energy security, protect the environment, and achieve sustainable development of economy and society. Renewable Energy Law will lead to an energy development transformation from traditional fossil to non-fossil new energy and diversified energy supply models.

In September 2007, the National Development and Reform Commission published Medium and Long-Term Development Plan for Renewable Energy in China (2007-2020) [1]. This plan specifically describes the current energy situation of China and the way of development in the future. The following aspects of renewable energy are included in this plan: development areas, investment estimation and benefit analysis. The significance of developing the renewable energy in China comes to four aspects. First, developing the renewable energy is building a resource-conserving society, and achieving sustainable development. Second, it's an important measure to protect the environment and address climate change. Third, it's an important measure to build a new socialist countryside. Fourth, it is an important option to explore new fields of economic growth, promote economic transition and create employment. There is a noticeable difference between China and other countries in the world about the third mentioned above. Historically, China has been attaching great importance to agriculture, since Three Rural Issues (rural areas, agriculture and farmers) [2] is an important factor on social harmony and stability. According to the sixth nationwide census in 2010, rural population is still approximately 674.15 million, accounting for about $50.32 \%$ of the total population. Statistical Communique of the 
People's Republic of China on the 2015 National Economic and Social Development [3] shows that the impoverished population in rural areas is about 55.75 million. Meanwhile, most of the rural labor-force flows into the city which has more employment opportunities and higher incomes, causing the hollowing out phenomenon in rural areas and the widening gap of the urban-rural dual structure. In view of this situation, developing renewable energy in rural areas has great significance for a balanced society.

In October 2014, the State Council and the National Energy Administration jointly issued Notice of the Implementation of the Work Plan for the Photovoltaic Poverty Alleviation Project [4]. This notice points out that it is necessary to develop distributed photovoltaic power generation in rural areas nationwide. Because it can not only increase incomes by selling electricity but also meet their own needs. Meanwhile, this measure will have a big influence on solving the problem of poverty, exploring domestic photovoltaic market and improving Chinese energy supply structure.

In March 2016, the National Development and Reform Commission, the State Council Leading Group Office of Poverty Alleviation and Development, the National Energy Administration, China Development Bank and Agricultural Bank of China jointly issued Opinions of the Implementation of the Photovoltaic Poverty Alleviation Work [5]. It clarifies the target of the work, that is: In approximately 35 thousand poor villages of 471 counties in 16 provinces, ensuring 2 million poor households without ability to work (including the disabled) increase incomes more than 3,000 yuan every household each year.

Under the strong impetus of national policy, many poor rural areas have been implementing photovoltaic poverty alleviation projects. So far, though the photovoltaic poverty alleviation is still in the early stage, it occupies a lot of social resources in the process of implementation. Many practical problems emerge in this process, such as policy adjustment between central ministries and local governments, regional electric balance between supply and demand, power grid access, interests between enterprises and villagers, and so forth.

Therefore, this study firstly refines and establishes the main influencing factors of policy in developing photovoltaic power generation in rural areas on the basis of prior study. Secondly, it evaluates and analyzes the photovoltaic poverty alleviation pilot project in Hejing County, Mongolian Autonomous Prefecture of Bayingolin, Xinjiang Uygur Autonomous Region. Lastly, it puts forward policy recommendations to the development of country's photovoltaic power generation projects in rural areas on the basis of analyzing the successful experience of the photovoltaic project "Ohisama Fund" in Iida City, Nagano Prefecture, Japan.

\section{Prior Studies}

\subsection{Relevant Prior Studies on Photovoltaic Power Generation in Rural Areas}

Yao Yebin et al. [6] proposed utilizing internet financing services in the study on financing of distributed photovoltaic power generation project. Wei Qiuli [7] discussed policies related to project scale, implementation, the matching of generation time to power utilization time in photovoltaic power generation project in rural areas and maintenance and emphasized the importance of policy mechanism.

\subsection{Prior Studies on Poverty Alleviation}

Yan Yan [8] analyzed the main reasons resulting in poverty, including severe geographical and natural conditions, resource scarcity, policy imbalance and unclear poverty objects. Liu Zhanfang et al. [9] analyzed the poverty in Xinjiang Uygur Autonomous Region. They mainly described phenomena of high poverty rate among national minorities, severe poverty in border areas, poor population concentrating in relatively fragile ecological environment, etc.

\subsection{Prior Studies on Poverty Alleviation with Photovoltaic Power Generation in Rural Areas}

Policy of poverty alleviation with photovoltaic power generation has been implemented for about 3 years. During this time, there are some representative prior studies. Zhang Baoyu et al. [10] deeply focused on equipment quality, product lifespan, transfer efficiency, operation maintenance, etc. in poverty alleviation with photovoltaic power generation. Then, they proposed to further improve the popularizing rate of electrification in rural areas and promote the combination of poverty alleviation with photovoltaic power generation with agricultural development. Guo Yuwei et al. [11] indicated that insufficient understandings on the policy of poverty alleviation with photovoltaic power generation, incomplete supervisory mechanism of electricity selling, lack of core equipment technology, difficulty in capital guarantee, low cognition among citizens, etc. are all important factors hindering the further development of poverty alleviation.

\subsection{Relevant Prior Study on the Evaluative Factors of Public Policies}

One of the main features of photovoltaic power generation project is the involvement of government, electric power company, enterprises, users and many other stakeholders, so this project has obvious property of public utility. Based on this opinion, the evaluative factors of public policies are also suitable for the evaluation of policies in photovoltaic power generation. In this aspect, important evaluative factors of public policies are extracted from analysis by $\mathrm{Wu}$ Haijuan [12] (Table 1). 
Table 1. Evaluative factors of public policies.

\begin{tabular}{|c|c|}
\hline Item & Factor \\
\hline & (1) Whether it can promote technology advancement \\
\hline Influences on social and economic & (2) Whether it can improve local economic development level \\
\hline development & (3) Whether it can optimize the supply, allocation and structure of local economic resources \\
\hline & (4) Whether it can meet the objective laws of energy-saving economy and green economy in the country and society \\
\hline Influences on natural environment & $\begin{array}{l}\text { (1) Whether it makes great contribution to surrounding environment and territorial resources } \\
\text { (2) Influences on urbanization and agricultural plantation }\end{array}$ \\
\hline $\begin{array}{l}\text { Influences on natural and ecological } \\
\text { environment }\end{array}$ & $\begin{array}{l}\text { (1) Whether it has severe effects on environment } \\
\text { (2) Whether it has environmental risks and sustainable mechanism of environmental decreasing effects } \\
\text { (3) Whether it damages the living environment of local residents }\end{array}$ \\
\hline Influences on social environment & $\begin{array}{l}\text { (1) Social infrastructure construction and medical insurance } \\
\text { (2) Territorial safety and public security }\end{array}$ \\
\hline
\end{tabular}

Source: Extract from $\mathrm{Wu}$ [12]

\subsection{Relevant Prior Studies on Evaluative Factors of Policies for Poverty Alleviation}

China has a vast area with 56 nationalities, so the development gap between different areas is large. Moreover, the national problem of the Zhuang nationality, Man nationality, Hui nationality, Uyghur nationality, Mongol nationality and other minorities which are concentrated in poverty areas in northwest, southwest, north and northeast of
China cannot be solved for a long time. The integration between nationalities and the narrowing of the gap between areas are big problems in social development of China. Among representative studies on poverty alleviation in minority areas, Lin Haiying [13] established the evaluative index system of poverty in minority areas. In this study, important evaluative factors are extracted from this index system (Table 2).

Table 2. Evaluative factors of poverty in minority areas.

\begin{tabular}{ll}
\hline Item & Factor \\
\hline Economic & (1) Annual household income \\
poverty & (2) Family-owned production means \\
& (3) Family-owned living materials \\
Information & (1) Popularization of television \\
poverty & (2) Popularization of radio \\
& (3) Utilization of Internet \\
Ecological & (1) Desertification area \\
poverty & (2) Incidence of natural disaster \\
Education & (3) Environmental input \\
poverty & (1) Average educated time of children in family \\
Traffic & (2) Condition of access to higher education \\
poverty & (1) Traffic means \\
\hline
\end{tabular}

Source: Extract from Lin [13]

\section{Analysis on Evaluative Factors of Policies Related to Distributed Photovoltaic Power Generation}

In this part, evaluative factors of policies related to distributed photovoltaic power generation in frontier rural areas of China are formulated according to the significance of renewable resource development, evaluative factors of public policies and evaluative index system for poverty alleviation in minority areas (Table 3 ). When evaluating policies of energy represented by photovoltaic power generation, the positioning of energy supply and security in diplomatic strategy is very important. Therefore, based on the items listed in Table 1, C. (influences on energy supply and security) is added in Table 3. When evaluating poverty alleviation policies, social stability of frontier rural areas and amalgamation between nationalities are also crucial factors. Therefore, based on the items listed in Table 2, a. (influences on social stability and national amalgamation) is added. In addition, in $b$. (influences on economy), the main factor controlling economic income b-(1) (employment) is added. As for the item d. (influences on education), the implementation of this project mainly makes villagers learn relevant policies and knowledge and skills of project, so the original evaluative factor is replaced by contribution to the popularization of knowledge and skills related to policies and projects. 
Table 3. Evaluative factors of policies related to distributed photovoltaic power generation in frontier rural areas of China.

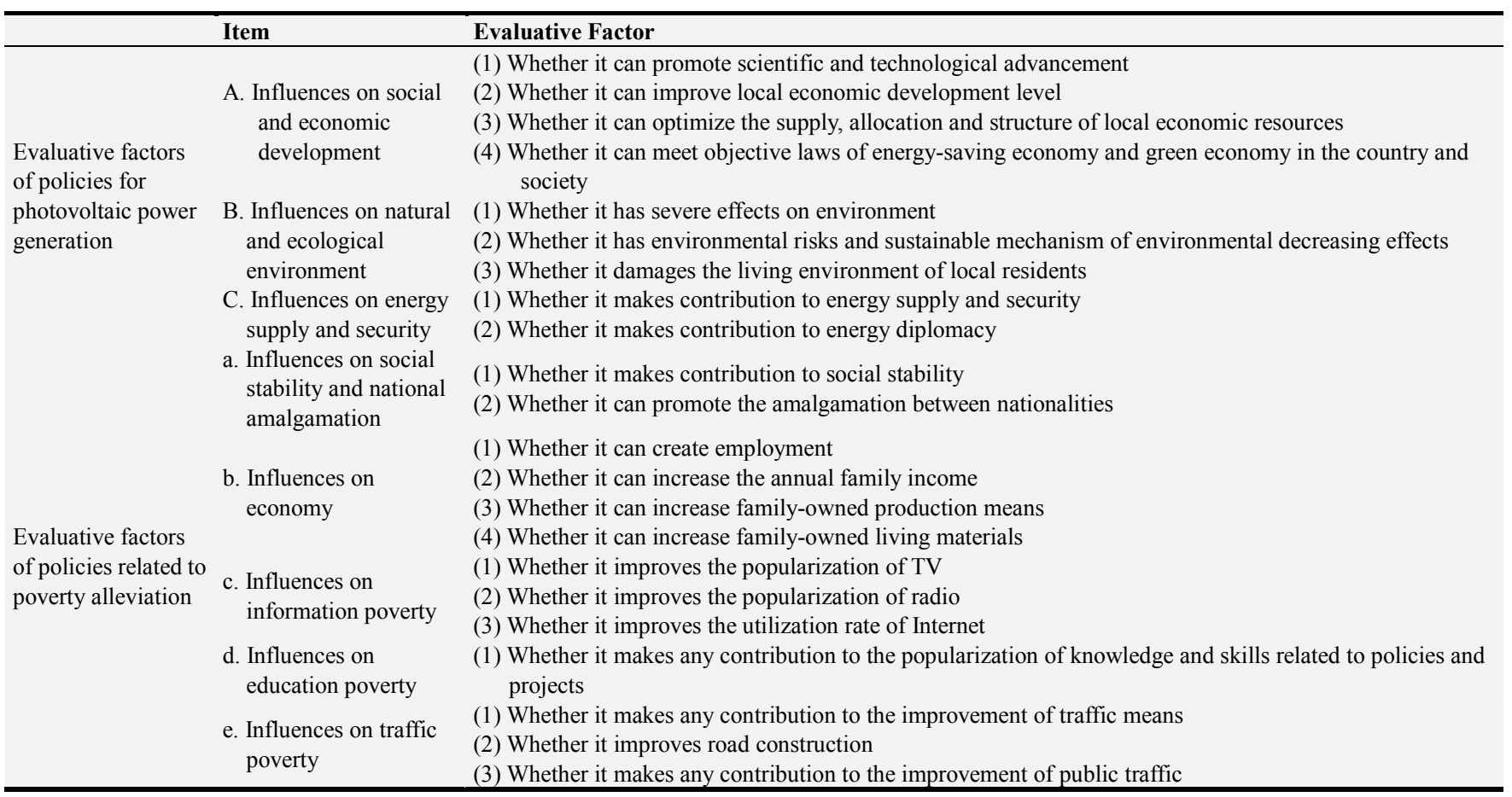

Table Constructed by Author

In the following study, evaluative factors above will be used to investigate and analyze the first pilot project for poverty alleviation with distributed photovoltaic power generation in Xinjiang Uygur Autonomous Region.

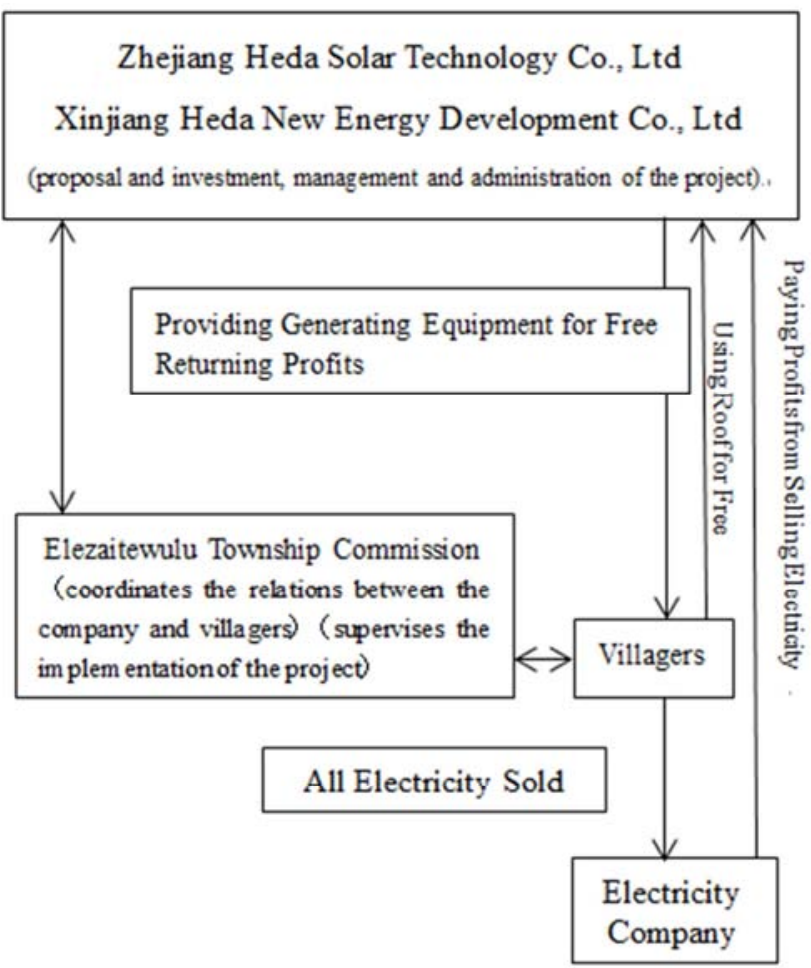

Figure 1. Project Overview Flowchart Constructed by Author.

\section{Analysis on Pilot Project for Poverty Alleviation with Photovoltaic Power Generation in Xinjiang}

\subsection{Project Overview}

Taking relatively poor Xinjiang Uygur Autonomous Region as a case study, the author investigated the first national pilot project for poverty alleviation with distributed photovoltaic power generation in this area in June 2016. The project is located in Chahanusu Village, Elezaitewulu Town, Hejing County, Mongolian Autonomous Prefecture of Bayingolin, Xinjiang Uygur Autonomous Region.

Zhejiang Heda Solar Technology Co., Ltd. and Xinjiang Heda New Energy Development Co., Ltd (hereinafter referred to as Xinjiang Heda Company), are two main companies in this project (Figure 1). Xinjiang Heda Company is responsible for the planning, investment, equipment supply, construction, operation and after-sale service of the project. Elezaitewulu Township Commission coordinates the relations between the company and villagers and supervises the implementation of the project.

\subsection{Investigation and Analysis on Pilot Project}

A. Influences on social and economic development

Firstly, for A-(1) (whether it can promote scientific and technological advancement) and A-(3) (whether it can optimize the supply, allocation and structure of local economic resources), patent product, solar photovoltaic panel manufactured by 
Zhejiang Heda Solar Technology Co., Ltd. is introduced to Xinjiang area through the implementation of this project. Therefore, technological advancement can be promoted and the supply, allocation and structure of market resources be optimized. For A-(2) (whether it can improve local economic development level), it contains Xinjiang Heda Company and many other manufacturing enterprises in the life cycle of this project to generate positive significance to the development and revitalization of renewable energy industry. Meanwhile, the implementation of this project can meet A-(4) (objective laws of energy-saving economy and green economy in the country and society).

B. Influences on natural and ecological environment

According to the project plan of Elezaitewulu Township Commission, the generating capacity in the first year will be up to $96,483 \mathrm{kWh}$ with the operating period of power generation facilities be 25 years. During this period, the generating capacity is about $2,194,123 \mathrm{kWh}$. In Xinjiang Uygur Autonomous Region, $0.36 \mathrm{~kg}$ coal is required to generate $1 \mathrm{kWh}$ thermal power to discharge $0.997 \mathrm{~kg} \mathrm{CO}_{2}$ (carbon dioxide), $0.03 \mathrm{~kg} \mathrm{SO}_{2}$ (sulfur dioxide), $0.272 \mathrm{~kg}$ TSP (total suspended particulate) and $0.015 \mathrm{~kg} \mathrm{NO}_{\mathrm{x}}$ (nitrogen oxide) (Table 4). After converting the emission reductions in this project, 790 tons of coal can be saved in 25 years with emission of 2,188 tons of $\mathrm{CO}_{2}, 65.8$ tons of $\mathrm{SO}_{2}, 597$ tons of TSP and 32.9 tons of $\mathrm{NO}_{\mathrm{x}}$ reducing. This project has positive effects on B-(1) (whether it has severe effects on environment) and B-(2) (whether it has environmental risks and sustainable mechanism of environmental decreasing effects). Usu is a village established for herdsmen suffering natural disasters. This village is located in the area where strong wind lasts long, while the annual precipitation is only $68 \mathrm{~mm}$ with dryness all the year round. This is actually the source of sand storm. According to the implementation of this project, the phenomenon, B-(3) (whether it damages the living environment of local residents) has not been found.

Table 4. Calculation of emission reductions in 25 years.

\begin{tabular}{llll}
\hline \multicolumn{4}{l}{ Analysis on emission reductions during operating period (25 years) } \\
\hline $\mathbf{C O}_{2}(\mathbf{t})$ & $\mathbf{S O}_{\mathbf{2}}(\mathbf{t})$ & $\mathbf{T S P}(\mathbf{t})$ & $\mathbf{N O}_{\mathbf{x}}(\mathbf{t})$ \\
\hline 2188 & 65.8 & 597 & 32.9 \\
\hline
\end{tabular}

Source: Technical Proposal of 76.5kW Distributed Photovoltaic Plant on the Residential Roofs of Elezaitewulu Township

\section{Influences on energy supply and security}

With rich minerals, natural gas, natural substances and other strategic resources, Xinjiang Uygur Autonomous Region is the amalgamation of ancient Chinese civilization, Indian civilization, Persian civilization and ancient Greek civilization. Therefore, Xinjiang has many similarities in culture, custom and other aspects with surrounding countries. When fully playing these advantages, the interconnection with Central-Asian countries may bring more possibilities to the development of Xinjiang. In September 2013, State President, Xi Jinping proposed "great conception of the Belt and Road (the Silk Road Economic Belt and the 21st-Century Maritime Silk Road)". The Silk Road Economic Belt goes via 18 countries covering 40 countries and benefiting more than 3 billion population. In terms of geographic location, Xinjiang is located in the central position of Asia neighboring with 8 countries, with the boundary line reaching the length of $5,600 \mathrm{~km}$. Meanwhile, Xinjiang is also the important hub of ancient Silk Road and the traffic fort of the Second Eurasian Land Bridge. From the perspective of geopolitics, the construction of the Silk Road Economic Belt can create economic prosperity, enhance political trust relationship with surrounding countries and promote cooperation between different areas to make contribution to sustainable development in Xinjiang Uygur Autonomous Region.

In this background, the development of distributed photovoltaic power generation in Xinjiang Uygur Autonomous Region can play a positive role in not only national development, but also the enlargement of power generation scale, the improvement of electric power storage, and the perfection of power grid. In the future, the project may possibly develop electricity transportation business to Central-Asian countries. As the channel connecting with the outside world in western China, Xinjiang Uygur Autonomous Region has great strategic significance in ensuring the stability of outside sources and energy import for its geographic position. Based on this opinion, the implementation of distributed photovoltaic power generation in Xinjiang Uygur Autonomous Region is not only beneficial to improve the poverty situations of villagers, but also significant to items $\mathrm{C}$-(1) (whether it makes contribution to energy supply and security) and C-(2) (whether it makes contribution to energy diplomacy).

a. Influences on social stability and national amalgamation

There are 23.6 million people in Xinjiang Uygur Autonomous Region (2015), composed of 47 nationalities, including the Uygur, the Han, the Kazak, the Kirgiz, the Dongxiang, the Mongol, the Xibe and many other nationalities. In addition, Xinjiang Uygur Autonomous Region is a gathering place of various religious cultures, including Islam, Buddhism, Christianity and so forth. Therefore, national antagonism and religious and cultural conflict which always happen are unstable factors in social development. Climate change, extreme weather, natural disaster, soil cracking, etc. caused by global warming make the nomadic nationalities lose their production means gradually. Up to now, poor villagers are still dependent on financial assistance to maintain their lives. In the long run, this measure just has temporary effects. Corresponding to it, the implementation of this project provides a sustainable way for poverty alleviation from the perspective of improving villagers' ability to live independently. Meanwhile, this project also increases the communication and understanding between government, enterprises (Han nationality) and villagers (Mongol nationality) while promoting friendly relations between nationalities. Therefore, this project has positive effects on a-(1) (whether it makes contribution to social stability) and a-(2) (whether it can promote the amalgamation between nationalities).

b. Influences on economy 
In this project, Xinjiang Heda Company agreed to return profits of RMB 600-3,000 to every household each year. The money would be a great economic support to villagers living with financial assistance. Therefore, this project makes great contribution to b-(2) (whether it can increase the annual household income). For b-(1) (whether it can create employment), during a one month construction period, Xinjiang Heda Company employed villagers to participate in the construction, paying RMB 120 to men and RMB 100 to women every day. This brought the considerable economic income to villagers. By analyzing current implementation situation, this project has not yet been effective in improving b-(3) (whether it can increase family-owned production means) and b-(4) (whether it can increase family-owned living materials).

c. Influences on information poverty and $\mathrm{d}$. Influences on education poverty

There are many reasons for poverty in Usu Village, including geographical and natural factors, the awareness of villagers and imbalance in national economic and social development. Villagers have mainly survived by nomadism and hunting without using domestic appliances for generations. Therefore, there are few channels for them to obtain outside information. This situation is very likely to be improved through the implementation of the project. Therefore, it could bring mitigation effects on c. (influences on information poverty). Moreover, villagers who participated in the construction may become experts in operating and maintaining the project, since they could learn knowledge of principles and product structures related to photovoltaic power generation. In the future, it is very possible that villagers will engage with the work of photovoltaic power generation and other renewable energy in frontier rural areas, even promising to be professional talents in this field someday. Therefore, this project is significant on d. (influences on education poverty).

e. Influences on traffic poverty

At present, this area still lacks public transport, so the main traffic means to Usu Village is by motor vehicle. As for e. (influences on traffic poverty), with the gradual increasing of visitors participating in logistics, construction and investigation of this project, it is promising that road construction and the introduction of public transport will be improved.

\section{Investigation on the Photovoltaic Power Generation Project in Iida City, Nagano Prefecture, Japan}

\subsection{General Situation of Iida City}

Iida City is located in the south of Nagano Prefecture, in the middle of Japan. It has a population of 103,472 (in January 2017), covering an area of 659 square kilometers, with an annual average temperature approximately $13.1^{\circ} \mathrm{C}$. The annual precipitation is about 1,767 millimeters and the annual sunshine time is 2,097 hours. It was rated as "Environmental Demonstrative City" in 2009. Iida City published relevant regulations for realizing regional sustainable development by introducing renewable energy in Iida on April 1, 2013.

\subsection{The Mechanism of the Ohisama Fund}

The Ohisama Fund is a mechanism that uses the capital raised from Japanese people to develop natural energy and returns the profits (including principal and interest) produced by the project to the investors (Figure 2). The capital is primarily invested in developing natural energy, especially photovoltaic power generation project, which makes a significant contribution towards preventing global warming.

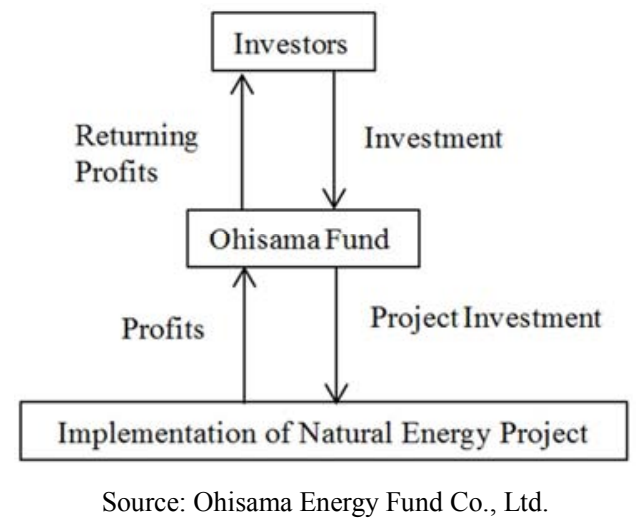

Figure 2. Mechanism of the Ohisama Fund Flowchart Constructed by Author:

\subsection{Advice on the Pilot Project of Xinjiang Uygur Autonomous Region from the Ohisama Fund}

By raising capital in Japan, the Ohisama Fund has promoted social cognition and understanding of the photovoltaic power generation project in Iida City while ensuring the capital used for the project. This initiative not only stimulates the investors' interests in this project, but also raises the public's concern about Iida City. For example, by inviting the investors to Iida City and holding "project visiting activities", it has played an important role in advertising the local customs and practices as well as enabling the investors acquainted with the operation of the project.

Aiming at the problem of financial difficulty in pilot project of Xinjiang Uygur Autonomous Region, it could be alleviated by absorbing external social funds or utilizing Internet financial services on the basis of referring to the experience of the Ohisama Fund. In view of the present situation, it is imperative to explore diversified financing channels when implementing distributed photovoltaic power generation projects in frontier rural areas of China.

\section{Conclusion}

This paper firstly refines evaluative factors of policies on the basis of prior study, and analyzes the main evaluative 
factors of poverty alleviation policies with distributed photovoltaic power generation of China. Then, by using these factors, the author investigates the first national pilot project for poverty alleviation with distributed photovoltaic power generation in Xinjiang Uygur Autonomous Region and analyzes the effectiveness of the project. According to the analysis, the implementation of this project has had a positive effect on different fields ranging from economy, environment, energy supply and security to politics, society and so forth. Finally, in view of the financial difficulty faced by the project, this paper puts forward constructive suggestions on the basis of referring to the experience of the Ohisama Fund in Iida City, Nagano Prefecture, Japan.

In policy evaluation of this project, it is worth noting that this project has had positive effects on China's energy security, energy diplomacy, national amalgamation and the popularization of relevant knowledge and skills among villagers. In order to further improve the policy effect of this project, it is necessary that we should not only import equipment to generate electricity, but more importantly, promote villagers' full participation in the implementation of the project. In the future, this region promises to be demonstrative area of China's distributed photovoltaic power generation project. In addition, villagers may become promotion experts and play an irreplaceable role in popularizing and exporting the project to other rural areas, which will improve their own identities as historically nomadic people who have been living with blessing of nature and the sun. At the same time, the better vision of further integration among nations could be achieved by villagers' contribution to national energy policy.

\section{Acknowledgements}

In field investigation, Mr. Huashan Heng, from Hejing County, and Mr. Guanglin Zhu, from Xinjiang Heda New Energy Development Co., Ltd, gave me great help. I wish to express my heartfelt gratitude to them.

\section{References}

[1] Medium and Long Term Development Plan for Renewable Energy in China (2007-2020), (2007, August). Retrieved March 7, 2017, from

http://www.ndrc.gov.cn/zcfb/zcfbghwb/200709/W0201402206 01800225116.pdf
[2] Wen, T. (2016, August 22). How Was the Three Rural Issues Raised. Retrieved April 18, 2017, from http://www.zgxcfx.com/jinritoutiao/89553.html

[3] 2015 National Economic and Social Development Report (Rep.). (2016, March 22). Retrieved March 7, 2017, from Tokoko Corp.

http://www.tokokosen.co.jp/information/report_pdf/201603No .259.pdf

[4] Notice of the Implementation of the Work Plan for the Photovoltaic Poverty Alleviation Project. (2014, October 11). Retrieved March 7, 2017, from

http://zfxxgk.nea.gov.cn/auto87/201411/t20141105_1862.htm

[5] Opinions of the Implementation of the Photovoltaic Poverty Alleviation Work (2016, March 23). Retrieved March 7, 2017, from

http://www.ndrc.gov.cn/zcfb/zcfbtz/201604/t20160401_79732 5.html

[6] Yao, Y., Huang, D., He, S., \& She, X. (2015). Analysis on Distributed Photovoltaic Financing Mode. Energy and Environment, (6).

[7] Wei, Q. (2013, May 6). Rural Photovoltaic Market Looks Beautiful. China Energy News, Retrieved March 7, 2017, from http://gb.oversea.cnki.net.ez.wul.waseda.ac.jp

[8] Yan, Y. (2016). Research on China's Regional Mode and Sustainable Path of Taking Targeted Measures to Help People Lift Themselves Out of Poverty. The Forum of Leadership Science, (23), pp.15-16.

[9] Liu, Z., \& Chun Mei, X. (2016). Research on Taking Targeted Measures to Help People Lift Themselves Out of Poverty in Minority Nationality Region-Taking Barkol Kazak Autonomous County of Xinjiang as an Example. Tribune of Social Sciences in Xinjiang, (5), pp. 29-35.

[10] Zhang, B., Su, Q., Lu, S., \& Xie, Y. (2016). Mode of Taking Targeted Measures to Help People Lift Themselves Out of Poverty-Analysis on the Effects of Poverty Alleviation with Photovoltaic Power Generation-Taking Jinzhai Country of Anhui Province as an Example. Fortune Today, (7), pp.87-89.

[11] Guo, Y., \& Li, Y. (2016). Strategic Significance and Popularization Measure of Poverty Alleviation by Photovoltaic Energy. Hubei Agricultural Sciences, 55(16).

[12] Wu, H. (2015). Analysis on Public Policy Evaluation System and Its Influencing Factors. Assets and Finances in Administration and Institution, (10), pp. 24-25.

[13] Lin, H. (2015). Build Evaluation Indicator System Poverty in Ethnic Minority Areas. Logistics Sci-Tech, (11), pp.17-19. 